\title{
The increase in $\mathrm{OH}$ rotational temperature during an active aurora event
}

\author{
H. Suzuki ${ }^{1}$, M. Tsutsumi ${ }^{2}$, T. Nakamura ${ }^{2}$, and M. Taguchi ${ }^{3}$ \\ ${ }^{1}$ Graduate University for Advanced Studies, 10-3 Midoricho, Tachikawa city, Tokyo, 190-8518, Japan \\ ${ }^{2}$ National Institute of Polar Research, 10-3 Midoricho, Tachikawa city, Tokyo, 190-8518, Japan \\ ${ }^{3}$ Rikkyo University, 3-34-1 Nishi-Ikebukuro, Toshima-ku, Tokyo, 171-8501, Japan
}

Received: 22 December 2009 - Accepted: 24 February 2010 - Published: 5 March 2010

\begin{abstract}
OH rotational temperatures have been observed at the Syowa Station, Antarctica $\left(69^{\circ} \mathrm{S}, 39^{\circ} \mathrm{E}\right)$, which is located in the middle of the auroral zone and has a highsensitivity spectrometer for the spectral region of the $\mathrm{OH} 8-4$ band. A dataset of 153 nights was acquired during the 2008 austral winter season. Of the 153 nights, the weather and aurora conditions were only suitable on 6 nights to study the relationship between auroral activity and $\mathrm{OH}$ airglow variation. Of these 6 nights, a significant increase in the rotational temperature and a decrease in the intensity related to an aurora activity were identified on the night of 27/28 March 2008, but no such variations were seen during the other nights. The horizontal magnetic field disturbance on the night of 27/28 March was the largest of that winter, while the cosmic radio noise absorption was also very strong. These facts indicate that, compared with the other nights, a large flux of highenergy auroral particles precipitated during the night. It is suggested that the observed variations in the $\mathrm{OH}$ rotational temperature and airglow intensity were caused by a lowering of the average airglow height as a result of $\mathrm{OH}$ depletion in the upper part of the layer where high-energy auroral particles can reach.
\end{abstract}

Keywords. Atmospheric composition and structure (Airglow and aurora; Middle atmosphere composition and chemistry) - Ionosphere (Auroral ionosphere)

\section{Introduction}

OH airglow, which was first discovered by Meinel (1950) as spectral line emissions followed by vibrational-rotational transitions, is one of the strongest emissions in the night sky. Using rocket-borne observations (e.g., Baker and Stair,

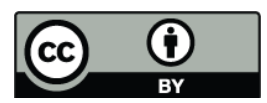

Correspondence to: H. Suzuki

(hsuzuki@nipr.ac.jp)
1988) and more recently using satellites (Zhang and Shepherd, 1999; Liu and Shepherd, 2006), the mean altitude of the $\mathrm{OH}$ airglow layer has been measured to be $87 \mathrm{~km}$, while the mean thickness has been measured to be $8 \mathrm{~km}$. Since reliable atmospheric temperature of the mesopause region can be remotely derived from the spectrum of the $\mathrm{OH}$ airglow, many observations of $\mathrm{OH}$ airglow have been performed in observatories around the world using various spectrometers and imagers (Sivjee et al., 1972; Krassovsky, 1972). However, few observations have aimed to detect an auroral effect on the $\mathrm{OH}$ airglow or rotational temperature. Harrison (1970) and Stubbs et al. (1983) reported on the relationship between aurora and OH airglow. However, Harrison (1970) found no considerable effect on $\mathrm{OH}$ airglow intensity correlated with the auroral $557.7 \mathrm{~nm}$ emission, which reached a luminosity of 10 to $20 \mathrm{kR}$. On the other hand, Stubbs et al. (1983) showed a $40 \mathrm{~K}$ increase in the rotational temperature after an active auroral event. However, they compared rotational temperatures recorded before and after active auroral events whose interval was $4 \mathrm{~h}$. This time interval is too long to distinguish temperature perturbations induced by atmospheric gravity waves from those caused by auroral activities.

The local effects of auroral precipitations on $\mathrm{OH}$ brightness or rotational temperature are not clear. Due the spectral overlap of the auroral and airglow emissions, it is difficult to study the relationship between aurora and $\mathrm{OH}$ airglow using optical methods. To study the relationship between the $\mathrm{OH}$ airglow and auroral activity, a fast spectrometer with a moderate spectral resolution is required. It was determined that the $\mathrm{OH} \mathrm{8-4} \mathrm{band} \mathrm{is} \mathrm{most} \mathrm{suitable} \mathrm{for} \mathrm{OH}$ rotational temperature measurements in the auroral zone. Thus, a spectrometer that could measure the $\mathrm{OH} 8-4$ band was developed to measure the $\mathrm{OH}$ rotational temperature at the Syowa Station, Antarctica $\left(69^{\circ} \mathrm{S}, 39^{\circ} \mathrm{E}\right)$ (Suzuki et al., 2009). Given the equipment's good spectral resolution and sensitivity, the $\mathrm{OH}$ rotational temperature can be derived every minute with an 

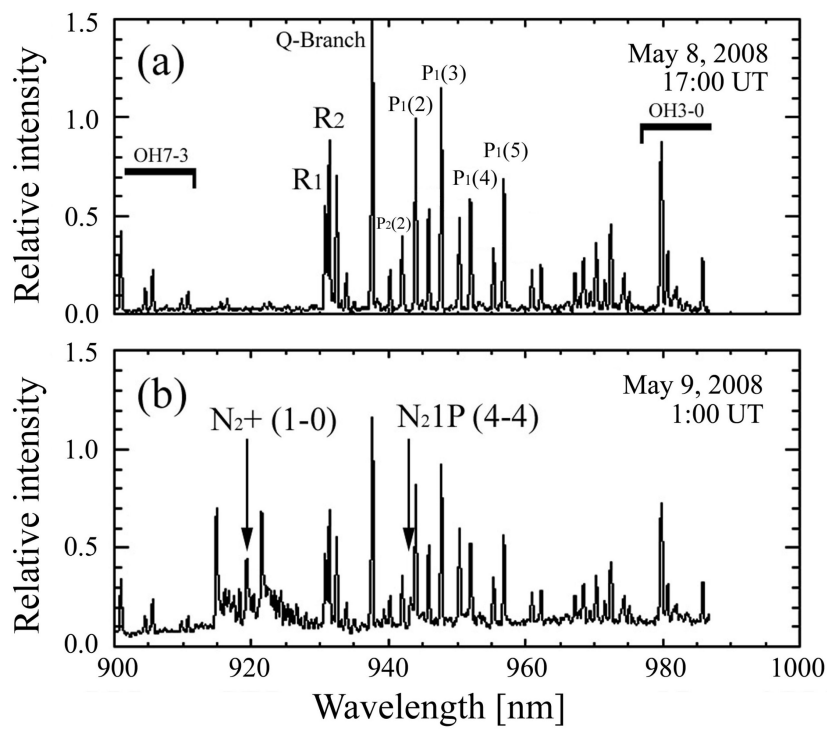

Fig. 1. Sample spectrum of the $\mathrm{OH} 8-4$ band obtained with a 1-min exposure. (a) Spectra correspond to quiet auroral conditions, while (b) spectra correspond to active auroral conditions.

accuracy of $\pm 2.0 \mathrm{~K}$. In this paper, data obtained from a significant $\mathrm{OH}$ rotational temperature increase event observed in 2008 are presented.

\section{Instrumentation and observations}

The spectrometer consists of a fast optical system (F1.7), a transmission grating as dispersion optics, and a highsensitivity CCD camera. The operating spectral region just covers the OH 8-4 band (900-990 nm), and a moderate spectral resolution of $0.27 \mathrm{~nm}$ is obtained. A back-illuminated $\mathrm{CCD}$ with an infrared enhanced $\mathrm{QE}$ is used as the imaging device. Sensitivity and spectral resolution of the spectrometer have been calibrated at the optical calibration facility in the National Institute of Polar Research, Japan. The instrument was installed in the Optical Building at the Syowa Station $\left(69^{\circ} \mathrm{S}, 39^{\circ} \mathrm{E}\right)$ in February 2008 by the 49th Japanese Antarctic Research Expedition. The narrow instrumental field-of-view, $4.5^{\circ}$ perpendicular to the magnetic meridian and $0.001^{\circ}$ along the magnetic meridian, is fixed at the local magnetic zenith. Nominal exposure time is $1 \mathrm{~min}$. Figure 1 shows sample spectra of the $\mathrm{OH} 8-4$ band obtained under quiet and active auroral conditions. Peak counts of the Qbranch are used as the measure of $\mathrm{OH}$ airglow intensity. The intensities of the rotational lines, $P_{1}(2), P_{1}(3)$, and $P_{1}(5)$, are used to derive the rotational temperature. The details of the method used to derive rotational temperature are described in Suzuki et al. (2009). Note that a weak auroral emission by N2 1PG overlaps the $\mathrm{OH}$ band. This auroral emission may cause contamination in the rotational temperature measurement. Two rotational temperatures were derived from
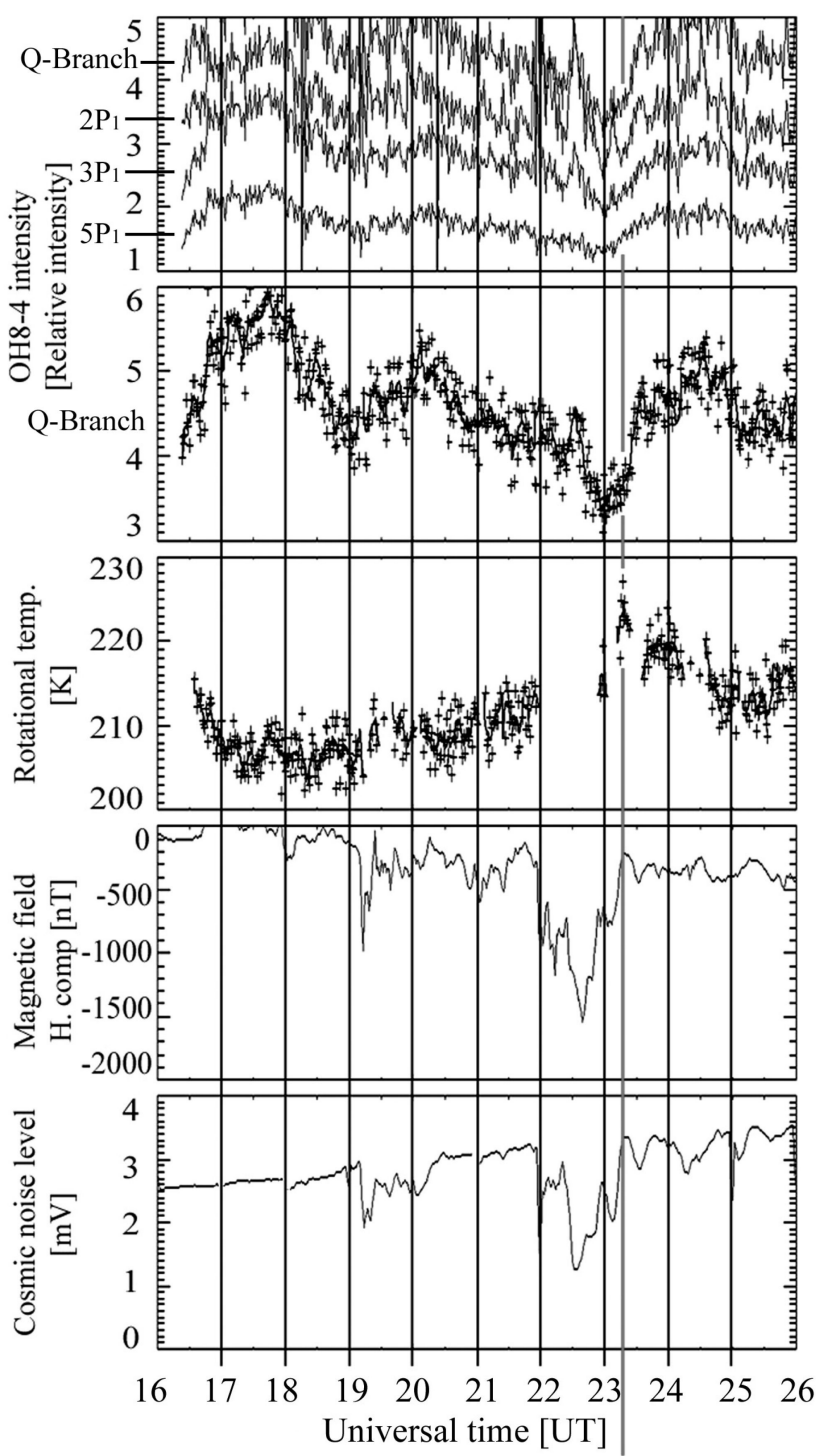

23:16

Fig. 2. Variations in the $\mathrm{OH}$ rotational temperature and intensity (upper two panels) observed on 27/28 March 2008. The intensity of the Q-branch, $\mathrm{P}_{1}(2), \mathrm{P}_{1}(3)$, and $\mathrm{P}_{1}(5)$ are also plotted in the upper panel. The second panel is the intensity of the Q-branch, which is the same as in the upper panel, but at a different scale. The horizontal component of the magnetic field and cosmic radio noise absorption (CNA) observed at the Syowa Station are displayed in the bottom two panels.

two pairs of rotational lines $\left(P_{1}(2) / P_{1}(5)\right.$ and $\left.P_{1}(3) / P_{1}(5)\right)$. If their difference is larger than $10 \mathrm{~K}$, the temperatures are omitted as inaccurate values due to auroral contamination.

\section{Results}

In 2008, OH airglow observations were performed for 153 nights, of which only 6 nights satisfied the requirement of 
clear weather and high auroral activity. Among these nights, variations of the rotational temperature and intensity of $\mathrm{OH}$ airglow that correlated with auroral activity were only seen on 27/28 March 2008, when the most active aurora during the 2008 winter period occurred. The highest K-index at the Syowa Station in 2008 was also recorded that night.

Figure 2 shows the variations in the $\mathrm{OH}$ rotational temperature and intensity observed on 27/28 March 2008. The horizontal component of the magnetic field and cosmic radio noise absorption (CNA) observed at the Syowa Station are displayed in the lower two panels. On this night, there was an auroral break-up which started at around 19:20 UT, followed by an even stronger break-up that started at around 21:50 UT. There were no remarkable variations in both intensity and rotational temperature during the first auroral break-up that lasted until 20:00 UT. The maximum variation recorded in the horizontal component of the magnetic field was about $1000 \mathrm{nT}$ during this period. The maximum drop of the cosmic radio noise level was about $1.8 \mathrm{~dB}(3.0 \mathrm{mV}$ to $2.0 \mathrm{mV})$. On the other hand, rapid and large variations were seen in both intensity and rotational temperature during the second auroral break-up that continued until 23:15 UT. Fortunately, the auroral arcs temporarily exited the field-of-view of the spectrometer for two short time periods around 23:00 UT and 23:16 UT, and valid temperatures were determined during these periods. Although there are no temperature data during most of the second auroral break-up period because of auroral contamination, it is obvious that the rotational temperature increased during the second break-up. The maximum variation recorded in the horizontal component of magnetic field was about $1500 \mathrm{nT}$, while the maximum drop in the cosmic radio noise level was about $4.3 \mathrm{~dB}(3.2 \mathrm{mV}$ to $1.2 \mathrm{mV})$ during the period.

The temperature around 22:57 UT was about $215 \mathrm{~K}$, but it was not much different from that just before the break-up at 21:55 UT. The rapid increase in temperature that occurred after 22:57 UT is remarkable and reached a peak temperature of about $225 \mathrm{~K}$ at 23:16 UT. In addition to the increase in temperature, a significant decrease in the intensity of $\mathrm{OH}$ airglow was also seen. The minimum of the $\mathrm{OH}$ airglow intensity corresponds almost to the maximum of the rotational temperature at 23:16 UT. The rapid increase in rotational temperature during the period from 22:00 to 23:40 UT seems to be related to the deep CNA event.

The visible auroral activity on this night is shown in Fig. 3. The color image shown in the upper panel is a keogram of visible aurora along the magnetic meridian. This keogram was made from a dataset obtained by a color digital camera (CDC) equipped with an all-sky fisheye lens. The curves plotted in the lower panel are luminosities of representative auroral emissions at the magnetic zenith observed by an allsky imager (ASI). ASI is equipped with a cooled CCD camera, a fast fisheye lens ( $f=6 \mathrm{~mm}, \mathrm{~F} 1.4)$, and a motor-driven filter turret with three band pass filters. The center wavelengths of the filters are $557.7 \mathrm{~nm}$ (OI emission), $630.0 \mathrm{~nm}$

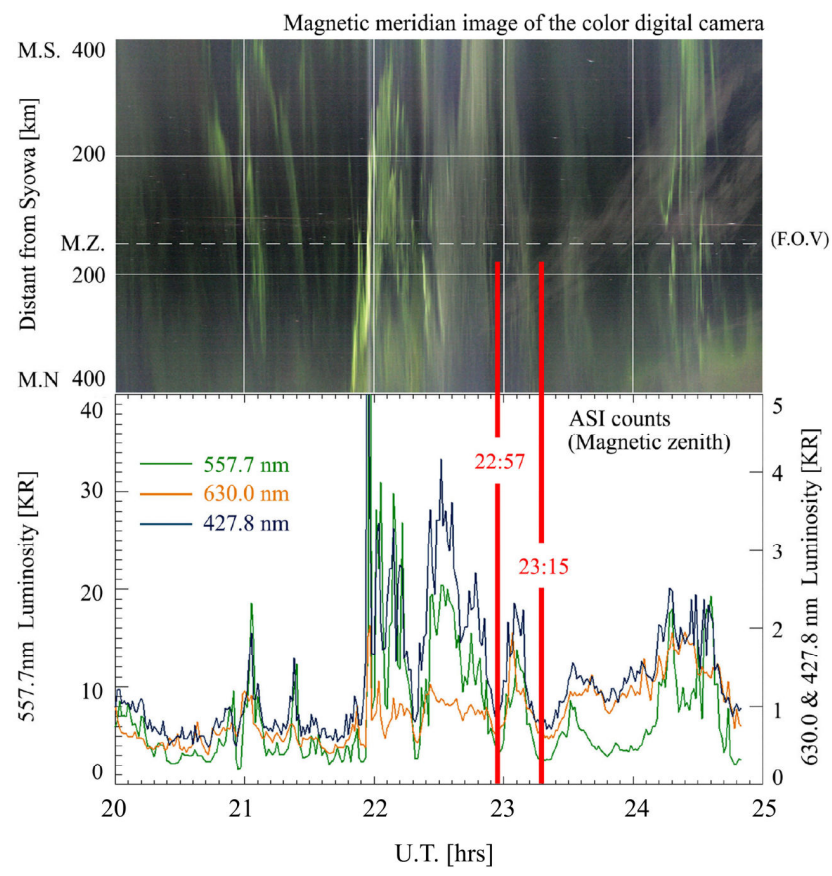

Fig. 3. Visible aurora activity on the night of 27/28 March 2008 observed by CDC (upper panel) and ASI (lower panel). M.N. represents the magnetic north pole, M.S. the magnetic south pole, and M.Z. the magnetic zenith. The lines plotted in the lower panel are the luminosity of the representative auroral emissions from the magnetic zenith observed by the ASI. Note that vertical scales for the intensities at $557.7 \mathrm{~nm}$ and 630.0 (or 427.8) nm are different.

(OI emission), and $427.8 \mathrm{~nm}\left(\mathrm{~N} 2^{+}\right.$emission). The details of the ASI are described in Okada et al. (1997). The broken line shown in the upper panel of Fig. 3 indicates the field-of-view of the spectrometer corresponding to the magnetic zenith direction. The temporal disappearance of the visible aurora from the field-of-view of the spectrometer at around 22:57 and 23:16 UT is confirmed in both the CDC and the ASI data. When Fig. 2 and the CNA data at the N2 ${ }^{+}(427.8 \mathrm{~nm})$ intensity shown in Fig. 3 are compared, it is seen that they are well-correlated and have a peak around 22:30 UT. These facts suggest that the auroral particle precipitation in the Dregion (about $90 \mathrm{~km}$ ) was enhanced at around 22:30 UT.

\section{Discussion}

According to theoretical works conducted by Gattinger and Vallance Jones (1972) and Rees and Luckey (1974), parameters of auroral precipitation such as an average energy and a total energy flux can be estimated by using ground-based observations of auroral emission intensities. The most familiar method is to use the intensity ratio of OI $630.0 \mathrm{~nm}$ (I(630.0)) to $\mathrm{N}_{2}^{+} 1 \mathrm{NG} 427.8 \mathrm{~nm}(\mathrm{I}(427.8))$, because the ratio depends on the energy of the incoming auroral electrons (Rees and Lucky, 1974; Ono, 1993). In the case shown in 


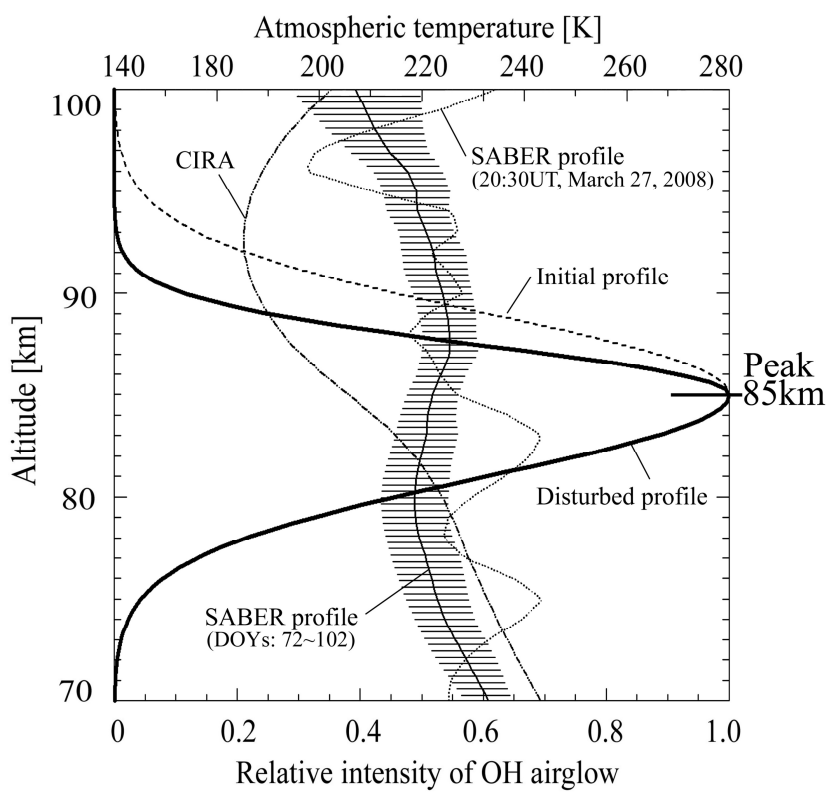

Fig. 4. Illustration of mechanisms which modify observable variations in rotational temperature and intensity of the $\mathrm{OH}$ airglow. The SABER temperature obtained near the Syowa station (dotted line), the 30-day averaged (thin solid line with error bars) temperature, and the zonal mean temperature (dot-dashed line) profile for March at $70^{\circ} \mathrm{S}$ obtained from the CIRA86 atmospheric model are plotted. The initial profile of the $\mathrm{OH}$ airglow emission rate is based on the data from the SABER/TIMED (see text).

the lower panel of Fig. 3, the ratio, I(630.0)/I(427.8) shows roughly 0.2 to 0.3 during 22:00 23:00 UT. This means the average energy of precipitating electron in this night reached from 10 to $20 \mathrm{keV}$ according to the model by Ono (1993). In addition the intensity of $427.8 \mathrm{~nm}$, which is sensitive to the high energy precipitations, was also high $(\sim 4 \mathrm{kR})$ during 22:00 23:00 UT in the night. This fact indicates that both precipitating energy and flux were especially high during the auroral event on 27/28 March.

Joule heating and particle heating by auroral precipitations are significant energy sources in the polar thermosphere. However, in general, it is unlikely that these processes can raise the temperature at the mesopause height (about $90 \mathrm{~km}$ ) because of the higher density of the atmosphere. The heat capacity of the neutral atmosphere at an altitude of $90 \mathrm{~km}$ is about $3 \times 10^{-3} \mathrm{~J} / \mathrm{K} \mathrm{m}^{3}$. This implies that the heating rate required to explain the temperature increase of $10 \mathrm{~K}$ during the $15 \mathrm{~min}$, which is the case shown in Fig. 2, is about $3.8 \times 10^{-5} \mathrm{~J} / \mathrm{s} \mathrm{m}^{3}$. This value is too high compared to previous Joule heating rates obtained using radar observation. For example, the Joule heating rate observed by the EISCAT (European Incoherent Scatter) radar at an altitude of $90 \mathrm{~km}$ is variable but has an order of $10^{-8} \mathrm{~J} / \mathrm{s} \mathrm{m}^{3}$ (e.g., Brekke, 1997). Particle heating by direct collision of auroral particles within the neutral atmosphere is possible if there are enough en- ergy flux depositions by the electron precipitations. According to Berger et al. (1970), the energy deposition of an energetic particle that has an incident energy of $20 \mathrm{keV}$ and pitch angle of $0^{\circ}$ deposits about $10^{-19} \mathrm{~J}$ per unit meter of penetration at an altitude of around $90 \mathrm{~km}$. Thus, a flux on the order of $10^{14} \mathrm{~m}^{-2} \mathrm{~s}^{-1}$ can maintain the required energy deposition of $10^{-5} \mathrm{~J} / \mathrm{s} \mathrm{m}^{3}$. However, this flux is also too large for highly energetic electrons $(>20 \mathrm{keV})$ compared to those calculated in previous work, which showed a flux on the order of less than $10^{10} \mathrm{~m}^{-2} \mathrm{~s}^{-1} \mathrm{keV}^{-1}$ at energies over $10 \mathrm{keV}$ (e.g. Brekke, 1983).

A typical mechanism that explains the fluctuations in the $\mathrm{OH}$ rotational temperature with a period of several minutes to hours is the passing of atmospheric gravity waves through the layer. In fact, the amplitudes and time scales of the order of the observed case (about $10 \mathrm{~K} / 15 \mathrm{~min}$ ) are often seen on auroral quiet nights at Syowa Station. However, as shown by Cho et al. (2006) and many ground observers, the phase value of the ground-observed intensity of the $\mathrm{OH}$ airglow and the rotational temperature show mostly a positive correlation with a small phase shift. This is due to the passing of an atmospheric gravity wave through the airglow layer accompanied by compression (expansion) and adiabatic heating (cooling) of the atmosphere. This relationship between the $\mathrm{OH}$ rotational temperature and the intensity of the $\mathrm{OH}$ airglow is discussed through a modeling study by Liu and Swenson (2003). The observed phase values shown in Fig. 2 are negatively correlated. This implies that the observed case is not caused by passing atmospheric gravity waves.

A possible mechanism that explains both the increase in rotational temperature and the decrease in the intensity of $\mathrm{OH}$ airglow is related to a change in the height distribution of the $\mathrm{OH}$ airglow emission. The rotational temperature derived from a ground-based observation is an averaged value over the $\mathrm{OH}$ airglow layer. Therefore, if temperature changes linearly with height, and a volume emission profile of the $\mathrm{OH}$ airglow has a symmetric shape relative to the peak height, the height integrated rotational temperature is equal to the temperature at the peak height. However, if the emission weakens in the upper part of the emission layer by hard auroral precipitations, the weighting profile of the $\mathrm{OH}$ layer is biased to the lower altitude relative to the peak height. Since a typical vertical temperature gradient of this region is negative, the lowering of the weight of an $\mathrm{OH}$ distribution causes an increase in the rotational temperature.

Figure 4 illustrates this mechanism. The initial profile is the $\mathrm{OH}$ volume emission rates synthesized from the data obtained by the SABER instrument onboard the TIMED satellite (details in Russell et al., 1999) on 27 March 2008. The data used to make the initial $\mathrm{OH}$ profile are averaged over the horizontal region within $500 \mathrm{~km}$ from the Syowa Station. The $\mathrm{OH}$ volume emission rate profile is then fitted by a Gaussian function. The Gaussian function is characterized by a peak of $85 \mathrm{~km}$, and a layer thickness of $8 \mathrm{~km}$ is plotted with a dashed line in Fig. 4. An example of the disturbed layer 
profile is also shown in Fig. 4 with a thick solid line where the upper part of the layer is decreased, and the total amount of the layer is $20 \%$ less than that of the initial conditions.

In addition to the background temperature, local dynamical effects such as gravity waves might be important. The temperature profile plotted with a dotted line is the SABER temperature of a tangential point, which is $60 \mathrm{~km}$ from the Syowa Station, observed at 20:30 UT on 27 March 2008. In this profile, a slightly negative gradient and vertical wave structures thought to be caused by gravity waves are seen. If this profile is assumed to be the background condition, the rotational temperature obtained from the ground-based observation under the initial and disturbed conditions are estimated to be $209 \mathrm{~K}$ and $211 \mathrm{~K}$. Thus, approximately $2 \mathrm{~K}$ of the observed temperature increase can be explained by this mechanism in this case. Even though this single temperature profile is that taken at a different location and time from the temperature increase event at Syowa, and the estimated increase is still smaller than the observed value, the significance of the local temperature structure can easily be determined based on this example.

Thus, the mechanism to explain the decrease in $\mathrm{OH}$ emission rate is still unknown. The possibility of a decrease in the $\mathrm{OH}$ emission rate during hard auroral precipitation was theoretically predicted by Maeda (1967). He reproduced the enhancement of the $\mathrm{O}_{2}$ dissociation by auroral electron bombardment followed by a decrease in the production rate of exited $\mathrm{OH}$ molecules using a time-dependent, 1-D chemical model. Since only the case for an extremely high energy flux with a characteristic energy of $100 \mathrm{keV}$ and a total number flux of $10^{14} \mathrm{~m}^{-2} \mathrm{~s}^{-1}$ is considered in this work, the decrease in the $\mathrm{OH}$ emission rate occurred over the entire layer. However, it is possible to reduce emissions in only the upper part of the $\mathrm{OH}$ emission layer, if appropriate hard precipitations are continued.

Finally, no other rotational temperature data obtained at the Syowa Station during 2008 show similar variations as for 27/28 March. The night of 27 March 2008 is the only case in which the $\mathrm{OH}$ airglow was disturbed by an auroral activity. Moreover, the large horizontal magnetic field disturbance, which gave the largest K-index at the Syowa Station during 2008, and the deep cosmic radio noise absorption recorded at Syowa Station indicate that the auroral activity during the night of 27/28 March was very high.

To further discuss the dominant mechanism of the observed phenomena, it is necessary to more precisely consider the effect of the aurora precipitations on the $\mathrm{OH}$ rotational temperature including dynamical and chemical effects using numerical simulation techniques. However, this is beyond the scope of present study and, thus, remains a potential avenue for future work. Nevertheless, the results of the present work indicate the possibility of an auroral effect on the $\mathrm{OH}$ rotational temperature and intensity accompanied with composition changes at the mesopause when auroral activity is very high. If the main mechanism for the increase in the rota- tional temperature is a height variation of the $\mathrm{OH}$ layer, such variations do not have to appear as a temperature increase all the time, but can appear as a temperature decrease depending on the local background temperature profile. Thus, simultaneous temperature profile observations combined with a lidar system are needed to further study this mechanism.

Acknowledgements. The authors would like to thank H. Shinagawa of the National Institute of Information and Communications Technology (NICT) and S. Oyama of the Solar-Terrestrial Environment Laboratory (STEL) of Nagoya University for their valuable discussion and comments related to this study.

The authors are grateful to the SABER team of the NASA/TIMED mission for providing the temperature and $\mathrm{OH}$ emission data sets.

Topical Editor C. Jacobi thanks D. Lummerzheim and C. Deehr for their help in evaluating this paper.

\section{References}

Baker, D. J. and Stair Jr., A. T.: Rocket measurements of the altitude distribution of the hydroxyl emission, Phys. Scr., 1(37), 611-622, 1988.

Berger, M. J. Seltzer, S. M., and Maeda, K.: Energy deposition by auroral electrons in the atmosphere, J. Atmos. Terr., Phys., 32, 1015-1045, 1970.

Brekke, A.: Joule heating and particle precipitation, Adv. Space Res., 2(10), 45-53, 1983.

Brekke, A.: Physics of the upper polar atmosphere, Wiley-Praxis Series in Atmospheric Physics, Praxis Publishing, United Kingdom, 1977.

Cho, Y.-M. and Shepherd, G. G.: Correlation of airglow temperature and emission rate at Resolute Bay $\left(74.68^{\circ} \mathrm{N}\right)$, over four winters (2001-2005), Geophys. Res. Lett., 33, L06815, doi:10.1029/2005GL025298, 2006.

Fleming, E. L., Chandra, S., Barnett, J. J., and Corney, M.: Zonal mean temperature pressure, zonal wind and geopotential height as functions of latitude, Adv. Space Res., 10(12), 11-59, 1990.

Gattinger, R. L. and Jones, V.: The intensity ratios of auroral emission features, Ann. Geophys., 28, 91-97, 1972.

Harrison, A. W.: Behavior of Hydroxyl Emission During Aurora, J. Geophys. Res., 75(7), 1330-1333, 1970.

Krassovsky, V. I.: Infrasonic variations of $\mathrm{OH}$ emission in the upper atmosphere, Ann. Geophys., 28, 739-746, 1972.

Liu, G. and Shepherd, G. G.: An empirical model for the altitude of the $\mathrm{OH}$ nightglow emission, Geophys. Res. Lett., 33, L09805, doi:10.1029/2005GL025297, 2006

Liu, A. Z. and Swenson, G. R.: A modeling study of $\mathrm{O} 2$ and $\mathrm{OH}$ airglow perturbations induced by atmospheric gravity waves, J. Geophys. Res, 108(D4), 4151, doi:10.1029/2002JD002474, 2003.

Maeda, K.: The auroral O2-dissociation and the infrared $\mathrm{OH}-$ emission, Ann. Geophys., 24, 173-184, 1968.

Meinel, A. B.: OH emission bands in the spectrum of the night sky, Astrophys. J., 111, 555-564, 1950.

Murphy, D. J., Forbes, J. M., Walterscheid, R. L., Hagan, M. E., Avery, S. K., Aso, T., Fraser,G. J., Fritts, D. C., Jarvis, M. J., McDonald, A. J., Riggin, D. M., Tsutsumi, M., and Vincent, R. A.: A climatology of tides in the Antarctic meso- 
sphere and lower thermosphere, J. Geophys. Res., 111, D23104, doi:10.1029/2005JD006803, 2006.

Okada, M., Ejiri, M., Okano, S., Taguchi, M., and Takeshita, S.: System Design and Initial Result of All Sky Imager at South Pole, Antarctic Record (Japanese), 41(3), 613-630, 1997.

Ono, T.: Derivation of energy parameters of precipitating auroral electrons by using the intensity ratio of auroral emissions, J. Geomag. Geoelectr., 45, 455-472, 1993.

Rees, M. H. and Luckey, D.: Auroral electron energy derived from ratio of spectroscopic emissions 1. Model computations, J., Geophys. Res., 79, 5158-5186, 1974.

Russel, J. M. V., Mlynczak, M. G., Gordley, L. L., Tansock, J., and Esplin, R.: An over view of the SABER experiments and preliminary calibration results, Proc. SPIE, 3756, 277-288, 1999.
Sivjee, G. G., Dick, K. K., and Feldman, P. D.: Temporal variations in night-time hydroxyl rotational temperature, Planet. Space Sci. 20, 261-269, 1972.

Stubbs, L. C., Boyd, J. S., and Bond, F. R.: Measurement of the $\mathrm{OH}$ rotational temperatures at Mawson, East Antarctica, Planet. Space Sci., 31, 923-932, 1983.

Suzuki, H., Taguchi, M., Kanai, Y., and Takeyama, N.: Fast spectrometer for ground-based observations of $\mathrm{OH}$ rotational temperature, Appl. Optics, 48(6), 1119-1127, 2009.

Zhang, S. P. and Shepherd, G. G.: The influence of the diurnal tide on the $\mathrm{O}(1 \mathrm{~S})$ and $\mathrm{OH}$ emission rates observed by WINDII on UARS, Geophys. Res. Lett., 26, 529-532, doi:10.1029/1999GL900033, 1999. 